\title{
Mucin Glycosylation and Sulphation in Airway Epithelial Cells Is Not Influenced by Cystic Fibrosis Transmembrane Conductance Regulator Expression
}

\author{
Shih-Hsing Leir, Simon Parry, Timea Palmai-Pallag, Joanne Evans, Howard R. Morris, Anne Dell, \\ and Ann Harris \\ Paediatric Molecular Genetics, Weatherall Institute of Molecular Medicine, University of Oxford, John Radcliffe Hospital, Oxford; \\ and Department of Biological Sciences, Imperial College London, London, United Kingdom
}

\begin{abstract}
Abnormalities in mucus properties and clearance make a major contribution to the pathology of cystic fibrosis (CF). Our aim was to test the hypothesis that the defects in CF mucus are a direct result of mutations in the $\mathrm{CF}$ transmembrane conductance regulator (CFTR) protein. We evaluated a single mucin molecule MUC1F/ 5ACTR that carries tandem repeat sequence from MUC5AC, a major secreted airway mucin, in a MUC1 mucin vector. To establish whether the presence of mutant or normal CFTR directly influences the O-glycosylation and sulphation of mucins in airway epithelial cells, we used the CFT1-LC3 ( $\Delta$ F508 CFTR mutant) and CFT1-LCFSN (wild-type CFTR corrected) human airway epithelial cell lines. MUC1F/5ACTR mucin was immunoprecipitated, centricon purified, and O-glycosylation was evaluated by Matrix-assisted laser desorption ionization and electrospray tandem mass spectrometry to determine the composition of different carbohydrate structures. Mass spectrometry data showed the same O-glycans in both CFTR mutant and wild-type CFTR corrected cells. Metabolic labeling assays were performed to evaluate gross glycosylation and sulphation of the mucins and showed no significant difference in mucin synthesized in six independent clones of these cell lines. Our results show that the absence of functional CFTR protein causes neither an abnormality in mucin O-glycosylation nor an increase in mucin sulphation.
\end{abstract}

Keywords: mucus; cystic fibrosis transmembrane conductance regulator; O-glycosylation; sulphation; airway

Respiratory failure in patients with cystic fibrosis $(\mathrm{CF})$ is due to recurrent lung infection and associated inflammatory damage, which is caused or exacerbated by failure to clear thick mucous secretions from the CF airway. Mucins are the major constituents of mucus and $\sim 20$ human mucins have been identified (1), which may be either membrane-tethered or secreted. Both of these types of mucin contribute to the glycoprotein content of mucous and have been implicated in CF pathology $(2,3)$. An important feature of human airway mucins is their post-translational modification by $\mathrm{O}$-glycosylation and sulphation, primarily within serine/ threonine-rich tandem repeats (TR), which constitute up to 70$80 \%$ of their mass, and is a major factor determining their biochemical and biophysical properties.

Whether the CF mucous secretions actually demonstrate increased viscosity is controversial. A number of studies report

(Received in original form September 28, 2004 and in final form December 20, 2004) This work was supported by the Cystic Fibrosis Trust, the Biotechnology and Biological Sciences Research Council (BBSRC) and the Wellcome Trust (Bair) (A.D.) and a Biomedical research collaboration grant (A.H.). A.D. is a BBSRC Professorial Research Fellow.

Correspondence and requests for reprints should be addressed to Ann Harris, Paediatric Molecular Genetics, Weatherall Institute of Molecular Medicine, University of Oxford, John Radcliffe Hospital, Oxford OX3 9DS, UK. E-mail: ann.harris@ paediatrics.ox.ac.uk

Am J Respir Cell Mol Biol Vol 32. pp 453-461, 2005

Originally Published in Press as DOI: 10.1165/rcmb.2004-0306OC on February 24, 2005

Internet address: www.atsjournals.org that there is no rheological defect in CF mucus (4-6). Others have shown abnormal rheology (7) that correlates with the degree of bacterial infection and $\mathrm{CF}$ disease severity (8) or that is only exhibited with increased DNA content (9) or altered salt concentration (10). Mucin abnormalities have been reported in patients with $\mathrm{CF}$, and it has been suggested that these result from mutations in the cystic fibrosis transmembrane conductance regulator (CFTR) protein having a direct effect on mucin biosynthesis. One hypothesis is that altered mucus properties may arise from primary changes in mucin glycosylation, through defective acidification of the trans-Golgi network altering the kinetics of $\mathrm{pH}$ sensitive glycoprotein-processing enzymes $(2,11,12)$. Alternatively, unusual mucin properties may simply be a consequence of volume-reduced airway surface liquid (ASL) (13).

Evidence for abnormalities in CF mucins comes from several types of studies; however, interpretation of the data in support of each hypothesis is controversial $(14,15)$. First, a number of groups have evaluated the biochemistry of mucins derived directly from patient and control secretions. CF intestinal mucins were found to be hyperglycosylated and to contain more fucose and sulfate than those from control subjects (16). Respiratory and salivary mucins from patients with CF may also exhibit elevated sulphation and aberrant sugar composition $(17,18)$. Interpretation of these data are complicated by the possibility that there were secondary modifications of the secreted mucin in vivo as a consequence of infection, inflammation, or pharmacologic intervention associated with $\mathrm{CF}$. Second, a number of groups have looked at mucin modifications in relevant cell lines or model systems derived from CF tissues. Studies using CF nasal epithelial cells (19) or a xenograft model (20) suggested that increased sulphation of mucus glycoproteins was a primary defect of disease that could be rectified by expression of wildtype CFTR (21). In contrast, other studies showed either no differences in sulphation or glycosylation of $\mathrm{CF}$ mucins in cell culture systems (22) or reported that changes could not be rescued by expression of wild-type CFTR (23). Data derived from individual cell lines must, however, be interpreted with caution because there are known differences in the activity of glycoprotein processing enzymes in cultured cells that are unconnected with mutations in CFTR (24). Activities of glycosyltransferases and sulphotransferases synthesizing mucin type O-glycans were shown to be CFTR-independent both in cell culture and in CFnull mice (25).

Effective therapeutic approaches to CF lung disease will probably be through pharmacologic intervention or by gene therapy. In both cases it is of considerable importance to understand if the altered properties/viscosity of CF mucins are due to defects in their biophysical and biochemical properties that arise inside airway epithelial cells (e.g., by changes in O-glycosylation) or outside these cells (e.g., by changes in ASL). The recurrent controversy relating to the cause of the abnormal properties of $\mathrm{CF}$ mucins has not produced a clear answer; hence, we have revisited the topic. 
We previously demonstrated that CFTR expression in general does not influence the gross levels of glycosylation or sulphation of the MUC1 mucin nor the types of carbohydrate structures attached to the MUC1 protein in the colon carcinoma cell line Caco2 (26). These studies were limited with respect to the organ site of origin of the cell lines evaluated (colon) and the fact that the only cell lines available for study were Caco-2 cell clones that expressed wild-type CFTR or had spontaneously switched off CFTR expression. We have now evaluated the O-glycosylation and sulphation of TR sequence from MUC5AC, a major secreted mucin in the airways (27), in appropriate matched sets of airway cells that express mutant or wild-type CFTR.

A full-length cDNA for MUC5AC has not been assembled, in part due to the size of the complete MUC5AC mRNA and the instability of the TR sequences (also evident at the nucleic acid level). There are specific antibodies that react with the MUC5AC TR (28); however, the reactivity of some of these may be modulated by glycosylation of the TR. Hence, to evaluate the O-glycosylation of the MUC5AC TR in airway cells, we previously developed a chimeric mucin in which MUC5AC TRs were inserted into an epitope (FLAG)-tagged MUC1 mucin backbone that lacked the native MUC1TRs (MUC1F/5ACTR) (29). MUC1F/5ACTR and other chimeric mucins were shown to be useful for evaluating the O-glycosylation of mucin TRs in vitro (29). The MUC1F/5ACTR construct was transfected into the CFT1-LC3 airway cell line, which is homozygous for the common $\triangle F 508$ mutation in CFTR, and a matched cell line CFT1-LCSFN, which has been stably transfected with wild-type CFTR (30). This experimental system has enabled evaluation of the O-glycosylation and sulphation of a single type of mucin TR in cells that express mutant or wild-type CFTR. Our data show that the presence of wild-type CFTR does not influence the O-glycosylation (including fucosylation and sialylation) or sulphation of the MUC1F/5ACTR mucin molecule. This suggests that mucin abnormalities arise outside the airway epithelial cell, either through altered ASL and/or extracellular factors influencing mucus properties, release, and clearance.

\section{MATERIALS AND METHODS}

\section{Cell Lines}

The CFT1-LC3 and CFT1-LCFSN cell lines (30) were kindly donated by Dr. J. Yankaskas (University of North Carolina, Chapel Hill). CFT1 are tracheal epithelial cell lines derived from a patient with CF (homozygous for the $\Delta 508$ mutation) that have been transformed with human papilloma virus E6/E7 genes. The CFT1-LC3 and CFT1-LCFSN cells were transformed with retroviral vector alone or containing the CFTR cDNA, respectively. Cells were grown in F12-7X medium (31).

\section{Generation of a Mammalian Expression Vector Carrying the Epitope-Tagged Chimeric MUC1F/5ACTR Construct}

Generation of the MUC1/MUC5AC chimera (MUC1F/5ACTR) was described previously (29). MUC1F/5ACTR contains 138 amino acids of MUC5AC TR cloned into the $B g l$ II and $A s p$ I sites of MUC1F $\Delta$ TR, a MUC1 cDNA that lacks native MUC1 TR sequences. In previous experiments the MUC1F/5ACTR cDNA was expressed from the $\beta$-actin promoter in the vector $\mathrm{pH} \beta$-APr1-neo. However, the neomycin resistance gene in this plasmid cannot be used in the CFT1-LC3 and CFT1LCSFN cells as they have previously been subjected to G418 selection (30). Instead, MUC1F/5ACTR was transferred as a Bam HI fragment, directly from $\mathrm{pBS}$ to the pcDNA3.1/zeo vector. DNA was purified by the Maxi plasmid purification kit (Qiagen, Crawley, UK).

\section{Stable Transfection of MUC1F/5ACTR}

The MUC1F/5ACTR plasmid was transfected into the CFT1-LC3 and CFT1-LCFSN cell lines with Lipofectin (Invitrogen, Paisley, UK). Stable transfectants were selected with Zeocin at $300 \mu \mathrm{g} / \mathrm{ml}$ for CFT1-LC3 or $150 \mu \mathrm{g} / \mathrm{ml}$ for CFT1-LCSFN, and clonal cell lines were isolated and the expression levels of MUC1F/5ACTR checked by Western blotting.

\section{Western Blotting}

Cell lysates were prepared in NET buffer (10 mM Tris pH 7.5, $150 \mathrm{mM}$ $\mathrm{NaCl}, 5 \mathrm{mM}$ EDTA) containing $1 \%$ (vol/vol) protease inhibitor cocktail (Sigma, Poole, UK) and 1\% (wt/vol) Triton X-100. Protein concentrations were determined using a detergent compatible DC protein assay (Bio-Rad, Hemel Hempstead, UK). Protein samples (crude lysate, $50 \mu \mathrm{g}$; purified, 10-15 $\mu \mathrm{g}$ ) were separated on SDS-PAGE gels (3\% stacker, $6 \%$ resolving), transferred to Immobilon-P transfer membrane (Millipore, Watford, UK), and blocked in blocking buffer (5\% skim milk powder in phosphate-buffered saline [PBS]) for $1 \mathrm{~h}$. M2 antibody (anti-FLAG epitope, Sigma) was used at a dilution of 1:1,500 in PBS with 1\% skim milk powder. Blots were incubated with the primary antibodies for $1 \mathrm{~h}$ at room temperature followed by three 10-min washes with PBS containing $0.1 \%$ Tween 20 ( $\mathrm{vol} / \mathrm{vol})$. The blots were incubated with horseradish peroxidase-conjugated rabbit anti-mouse IgG secondary antibody (DAKO, Ely, UK) in PBS with $1 \%$ skim milk powder for $1 \mathrm{~h}$ followed by washing with PBS- $0.1 \%$ Tween 20 (vol/vol) as described above. Blots were visualized using ECL reagents (Amersham, Little Chalfont, UK) applied according to the manufacturer's instructions and exposed to ECL-sensitive film.

\section{Evaluation of CFTR Expression}

CFTR expression in MUC1F/5ACTR-transfected CFT1-LC3 and CFT1-LCFSN clones was evaluated by semiquantitative RT-PCR, using primers E1R and E1L, and quantitative RT-PCR (Taqman) as described previously $(32,33)$. The semiquantitative RT-PCR method was modified by using ramped annealing temperatures: annealing for $2 \mathrm{~min}$ at $54^{\circ} \mathrm{C}$ for 5 cycles, at $56^{\circ} \mathrm{C}$ for 5 cycles, at $58^{\circ} \mathrm{C}$ for 10 cycles, and finally at $60^{\circ} \mathrm{C}$ for 16 cycles. All other parameters of the RT-PCR reaction were as published (33).

\section{Immunoprecipitation}

MUC1F/5ACTR glycoconjugates were purified with M2-antibody against the FLAG epitope; $20 \mu \mathrm{l}$ of M2-conjugated agarose beads (Sigma) were incubated with $300 \mu \mathrm{g}$ of cell lysate at $4^{\circ} \mathrm{C}$ for $24 \mathrm{~h}$ with vigorous shaking. The agarose beads were washed twice in NET buffer $(50 \mathrm{mM}$ Tris, $150 \mathrm{mM} \mathrm{NaCl}, 1 \mathrm{mM}$ EDTA, $\mathrm{pH}$ 7.4), and protein was eluted from the beads by incubation with $50 \mu$ of FLAG peptide $(500 \mu \mathrm{g} / \mathrm{ml}$; Sigma) for $24 \mathrm{~h}$ at $4^{\circ} \mathrm{C}$ with vigorous shaking.

\section{Mass Spectrometry}

Preparation of oligosaccharides. O-linked oligosaccharides were liberated from the immunoprecipitated mucins by reductive elimination $(400 \mu \mathrm{l}$ of $1 \mathrm{M} \mathrm{NaBH}_{4}$ in $0.05 \mathrm{M} \mathrm{NaOH}$ at $45^{\circ} \mathrm{C}$ for $16 \mathrm{~h}$ ) and desalted through a Dowex 50W-X8 $(\mathrm{H})$ column. Removal of traces of detergent was achieved by passing the desalted eluate through a Sep-Pak C18 column (Waters, Elstree, Herts, UK). Excess borates were removed by coevaporation with $10 \%(\mathrm{vol} / \mathrm{vol})$ acetic acid in methanol under a stream of nitrogen.

Matrix-assisted laser desorption ionization "time-of-flight" analysis. Chemical derivatization was performed as described previously (29). Matrix-assisted laser desorption ionization "time-of-flight" (MALDITOF) data were acquired by using a Voyager-DE STR mass spectrometer (PerSeptive Biosystems, Framingham, MA) in the reflectron mode with delayed extraction. Permethylated samples were dissolved in $10 \mu \mathrm{l}$ of $80 \%(\mathrm{vol} / \mathrm{vol})$ methanol in water, and $1 \mu \mathrm{l}$ of dissolved sample was premixed with $1 \mu \mathrm{l}$ of matrix/2,5-dihydroxybenzoic acid before loading onto a metal plate.

Collisionally activated dissociation electrospray tandem mass spectrometry. Collisionally activated dissociation electrospray tandem mass spectrometry (CAD ES-MS/MS) spectra were acquired using a Q-TOF (Micromass, Manchester, UK) instrument. The permethylated glycans were dissolved in methanol before loading into a spray capillary coated with a thin layer of gold/palladium, inner diameter $2 \mu$ l (Proxeon, Odense, Denmark). A potential of $1.5 \mathrm{kV}$ was applied to a nanoflow tip to produce a flow rate of $10-30 \mathrm{nl} / \mathrm{min}$. The drying gas used was $\mathrm{N}_{2}$ and the collision gas was argon, with the collision gas pressure maintained at $10^{-4}$ millibar. Collision energies varied depending on the size of the carbohydrate, typically between 30 and $90 \mathrm{eV}$. 


\section{Metabolic Labeling Assays}

All metabolic labeling experiments were performed in triplicate. Relative levels of glycosylation per unit protein were determined. Cell lines were grown to $\sim 40 \%$ confluence in T75 flasks and washed three times in PBS, and then $10 \mathrm{ml}$ of F12 medium containing $7 \mathrm{X}$ supplement was placed in each flask with $0.015 \mathrm{MBq} / \mathrm{ml}\left[\mathrm{U}_{-}{ }^{14} \mathrm{C}\right]$ protein hydrolysate (CFB25; Amersham), and $0.051 \mathrm{MBq} / \mathrm{ml} \mathrm{d}-\left[6-{ }^{3} \mathrm{H}\right]$ glucosamine hydrochloride (TRK398; Amersham). The cells were grown to confluence over $4 \mathrm{~d}$, cell lysates were prepared and MUC1F/5ACTR mucin immunoprecipitated with the M2 antibody as described above. The immunoprecipitated material was separated on SDS-PAGE gels and visualized by autoradiography after treatment with the fluorographic agent Amplify (Amersham) and gel areas containing the MUC1F/5ACTR glycoprotein were excised. The amount of ${ }^{14} \mathrm{C}$ amino acids and ${ }^{3} \mathrm{H}$ glucosamine present in these gel slices was determined by scintillation counting. Counts were then expressed as ratios comparing the level of glycosylation $\left({ }^{3} \mathrm{H}\right.$ glucosamine) to the level of protein $\left({ }^{14} \mathrm{C}\right.$ amino acids).

The relative level of sulphation was compared with the level of glycosylation. Cell cultures at $40 \%$ confluence were prepared as for glycosylation assays. F12 medium containing 7X serum-free supplement was used with $0.296 \mathrm{MBq} / \mathrm{ml}\left[{ }^{35} \mathrm{~S}\right] \mathrm{Na}_{2} \mathrm{SO}_{4}$ (SJ162; Amersham) and $0.051 \mathrm{MBq} / \mathrm{ml}$ d- $\left[6-{ }^{3} \mathrm{H}\right]$ glucosamine hydrochloride, and the cells grown to confluence over $4 \mathrm{~d}$. Lysates were prepared as described for unlabeled cells, and the MUC1F/5ACTR glycoprotein was purified by immunoprecipitation with the M2 antibody. The immunoprecipitated material was separated on SDS-PAGE gels and visualized by autoradiography as described for the ${ }^{14} \mathrm{C}$ amino acids ${ }^{\beta} \mathrm{H}$ glucosamine experiments. The gel areas containing the MUC1F/5ACTR glycoprotein were excised. The amounts of ${ }^{35} \mathrm{~S}$ sulfate and ${ }^{3} \mathrm{H}$ glucosamine were determined by scintillation counting the excised gel slices. These counts were expressed as ratios comparing the level of glycosylation ( ${ }^{3} \mathrm{H}$ glucosamine) to the level of sulphation ( ${ }^{35} \mathrm{~S}$ sulfate).

The levels of sulphation of the mucin proteins were also determined by using F12 medium containing 7X serum-free supplement with 0.296 $\mathrm{MBq} / \mathrm{ml}\left[{ }^{35} \mathrm{~S}\right] \mathrm{Na}_{2} \mathrm{SO}_{4}$ and $0.093 \mathrm{MBq} / \mathrm{ml}\left[{ }^{3} \mathrm{H}\right]$ amino acids $(37 \mathrm{MBq} / \mathrm{ml}$; MP Biomedicals, Irvine, CA). The cells were grown to confluence over $4 \mathrm{~d}$ and samples were prepared as described as above. The amounts of ${ }^{35} \mathrm{~S}$ sulfate and ${ }^{3} \mathrm{H}$ amino acids in excised gel slices were determined. These counts were expressed as ratios comparing the level of ${ }^{35} \mathrm{~S}$ sulfate to ${ }^{3} \mathrm{H}$ amino acids.

\section{RESULTS}

\section{Expression of MUC1F/5ACTR in CFT1-LC3 and CFT1-LCSFN Airway Epithelial Cells}

Stably transfected clones of CFT1-LC3 and CFT1-LCSFN carrying MUC1F/5ACTR (Figure 1) were screened for chimeric

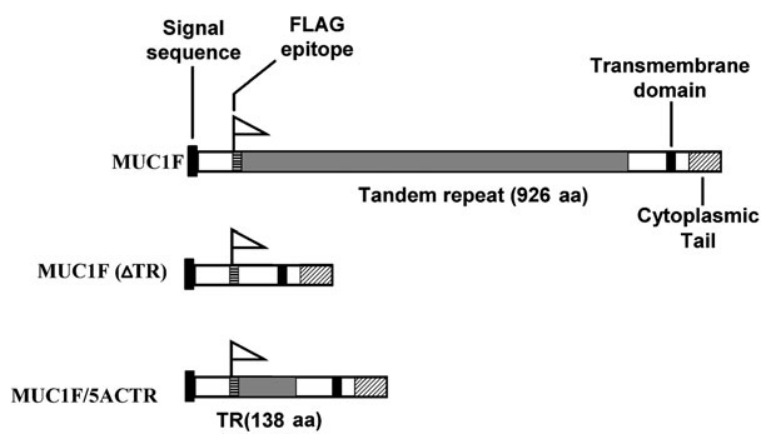

Figure 1. Diagram of epitope-tagged MUC1F/5ACTR mucin. MUC1F/ 5ACTR was generated from MUC1F as described previously (29). The position of the FLAG (M2) epitope is marked above. Dark gray rectangles indicate TR sequence. Signal sequence, membrane spanning and cytoplasmic tail domains are also indicated. MUC1F $(\triangle T R)$ and the chimeric mucin MUC1F/5ACTR (which contains MUC5AC TR) are illustrated below MUC1F. The figure is drawn to scale.

mucin expression by Western blotting of SDS/PAGE gels (Figure $2 \mathrm{~A})$. To exclude changes in mucin processing resulting from clonal variation, we evaluated mucin from three clones of each cell line carrying the same chimeric mucin. The three clones of CFT1-LC3 carrying MUC1F/5ACTR included one with low levels of MUC1F/5ACTR expression (L15) and two with highlevel expression (L23 and L28) (Figure 2). Similarly, one clone of CFT1-LCFSN expressing low levels of MUC1F/5ACTR (C03) and two with high-level expression ( $\mathrm{C} 13$ and $\mathrm{C} 16)$ were chosen for further evaluation (Figure 2A). As observed previously for the expression of FLAG-tagged chimeric mucins in other cell types $(29,34)$ multiple forms of MUC1F/5ACTR mucin were detected in CFT1-LC3 and CFT1-LCFSN cell clones. The major form of the MUC1F/5ACTR mucin migrated between 130 and $150 \mathrm{kD}$ in these cells, a rather smaller observed mass than seen previously in $\mathrm{Caco} 2$ colon carcinoma cells. However, this difference in migration might reflect different glycosylation of the MUC1F/5ACTR mucin in the airway cells. No significant differences were detected in the migration of MUC1F/5ACTR forms expressed in the CFT1-LC3 and CFT1-LCFSN cells.
A



Figure 2. Expression of the MUC1F/5ACTR mucin and CFTR in CFT1LC3 and CFT1-LCFSN airway cells. (A) Western blot analysis of MUC1F/ 5ACTR chimeric mucins immunoprecipitated from whole cell lysates (CFT1-LC3 clones L15, L23, and L28 and CFT1-LCFSN clones C03, C13, and C16) and separated by 3\%/6\% SDS-PAGE. Detection was by M2 anti-FLAG antibody followed by rabbit anti-mouse IgG conjugated to HRP. Migration of Full Range Rainbow protein molecular weight markers is indicated $(\mathrm{kD})$. Mucins immunoprecipitated with an excess of M2 beads from $300 \mu \mathrm{g}$ of total cell lysate were loaded in each lane. (B) Semiquantitative RT-PCR for CFTR mRNA. The 768-bp CFTR-specific product is marked by an arrow. For each RT-PCR reaction $2 \mu \mathrm{g}$ of total RNA was used. Lane M, 1-kb ladder; lane 1, LCFSN; lane 2, clone C03; lane 3, clone C13; lane 4, clone C16; lane 5, clone L15; lane 6, clone L23; lane 7, clone L28; lane 8, no reverse-transcriptase control. 
To confirm that the MUC1F/5ACTR mucin-expressing clones derived from the CFT-LC3 and CFTR-LCFSN cell lines accurately reflected the CFTR mRNA expression status of the parental lines, semiquanititative and quantitative RT-PCR were performed. Figure 2B shows by semiquantitative RT-PCR that, as expected, the $\mathrm{C} 03, \mathrm{C} 13$, and $\mathrm{C} 16$ lines showed abundant transgenederived CFTR mRNA expression, whereas the L15, 23, and 28 lines showed much lower, though detectable, expression of endogenous CFTR. Quantitative RT-PCR data confirmed the differential expression levels (data not shown). This is consistent with the expression levels of CFTR in the original description of the parental cell lines (30).

\section{Evaluation of the MUC1F/5ACTR O-Glycans Expressed in CFT1-LC3 and CFT1-LCFSN Cell Clones by Mass Spectrometry}

O-glycans were prepared from MUC1F/5ACTR mucin immunoprecipitated from clones CFT1-LC3 L15 and L28 and CFT1LCFSN $\mathrm{C} 03$ and $\mathrm{C} 13$. After reductive elimination, O-glycans were purified using Dowex and Sep-Pak C18 columns, prepared as permethylated derivatives and analyzed by MALDI-TOF mass spectrometry (Figure 3). Both CFTR-mutant (CFT1-LC3) and -corrected (CFTR1-LCSFN) cell lines showed 12 peaks that correlated to known O-glycan structures (Figures 3A and 3B; Table 1 ). The compositions uniquely attributable to core 1 structures
(35) include $\mathrm{Hex}_{1} \mathrm{HexNAc}_{1}$-ol (m/z 534), Fuc $\mathrm{Hex}_{1} \mathrm{HexNAc}_{1}$-ol (m/z 708), NeuAc $\mathrm{Hex}_{1} \mathrm{HexNAc}_{1}$-ol (m/z 895), and NeuAc $\mathrm{c}_{2} \mathrm{Hex}_{1}$ $\mathrm{HexNAc}_{1}$-ol $(\mathrm{m} / \mathrm{z}$ 1,256). Additional peaks were observed at $\mathrm{m} / \mathrm{z}$ $983\left(\mathrm{Hex}_{2} \mathrm{HexNAc}_{2}-\mathrm{Ol}\right), \mathrm{m} / \mathrm{z}$ 1,157 $\left(\mathrm{Fuc}_{1} \mathrm{Hex}_{2} \mathrm{HexNAc}_{2}-\mathrm{ol}\right), \mathrm{m} / \mathrm{z}$ 1,344 (NeuAc $\left.\mathrm{Hex}_{2} \mathrm{HexNAc}_{2}-\mathrm{ol}\right), \mathrm{m} / \mathrm{z} 1,432\left(\mathrm{Hex}_{3} \mathrm{HexNAc}_{3}\right.$-ol), m/z 1,518 $\left(\mathrm{NeuAc}_{1} \mathrm{Fuc}_{1} \mathrm{Hex}_{2} \mathrm{HexNAc}_{2}\right.$-ol), m/z 1,606 (Fuc $\mathrm{Hex}_{3}$ $\mathrm{HexNAc}_{3}-\mathrm{ol}$ ), m/z 1,705 ( $\mathrm{NeuAc}_{2} \mathrm{Hex}_{2} \mathrm{HexNAc}_{2}$-ol), and m/z 1,793

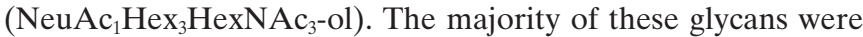
shown to be core 2 (35) by CAD ES-MS/MS. For both clones, CFT1-LC3 L28 and CFT1-LCFSN C13 m/z 895 and m/z 983 were abundant peaks. Though minor differences were seen in the relative abundance of some of the peaks between the two spectra shown in Figure 3 (and between these and the spectra for clones CFT1-LC3 L15 and CFT1-LCFSN C03, (not shown)), these are likely to reflect individual clonal variation or sample abundance differences rather than a consistent difference between the CFTR + and CFTR - lines. The only consistent difference between the clones was a reduction in the relative amounts of the higher $\mathrm{m} / \mathrm{z}$ structures in the CFTR - cell lines, which probably reflects the lower amount of mucin analyzed. Where sufficient material was available, the sequences of glycans whose compositions represent both core 2 and extended core 1 structures were defined by CAD ES-MS/MS. Representative data are shown for the compositions at $\mathrm{m} / \mathrm{z} 1,157, \mathrm{~m} / \mathrm{z} 1,344$, and $\mathrm{m} / \mathrm{z}$ 1,432 (Figure 4) and confirmed the structural predictions shown
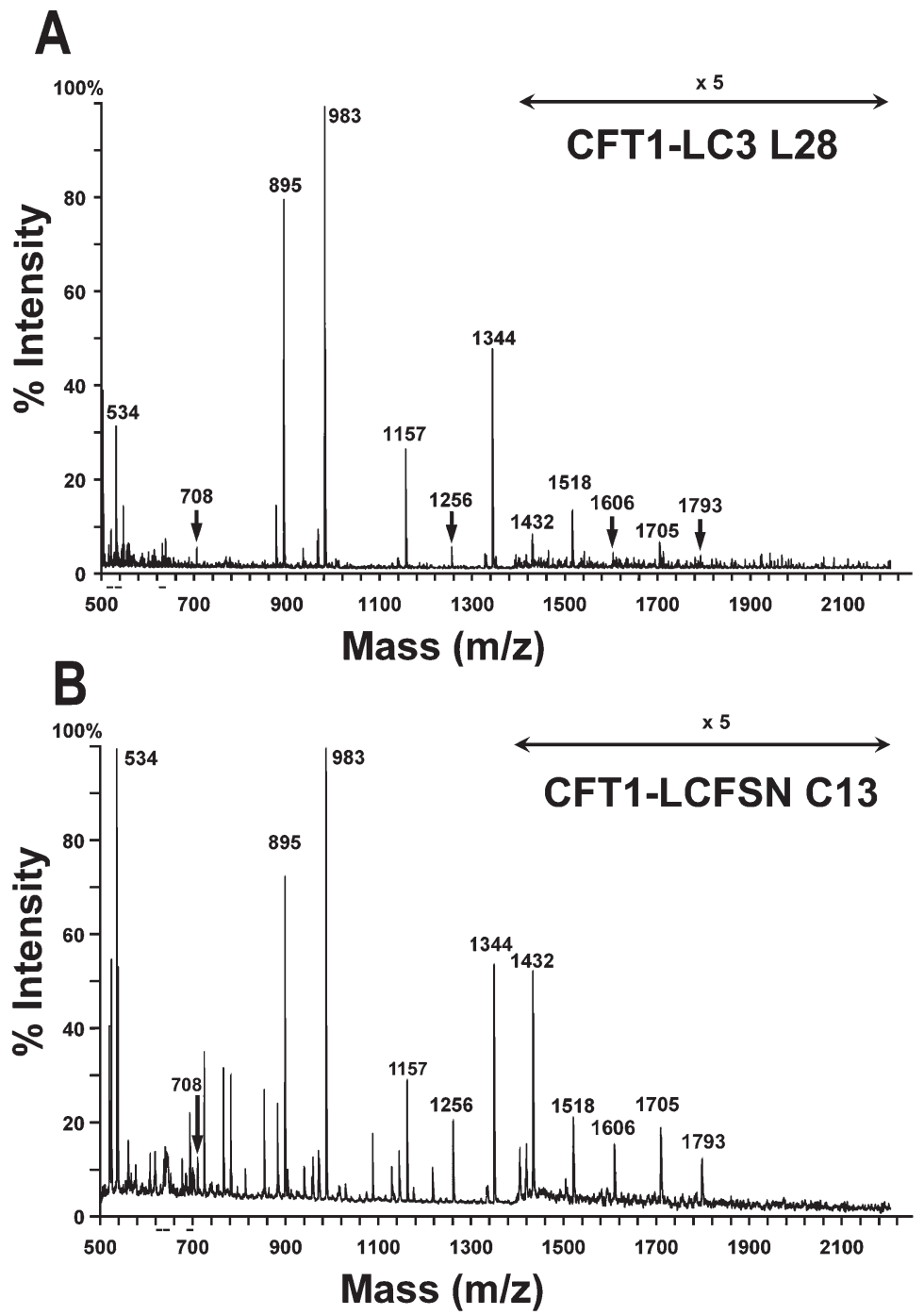

Figure 3. MALDI-TOF MS spectra of the MUC1F/5ACTR O-glycans. Mucin O-glycans were released by reductive elimination, purified by Dowex and Sep-Pak C18 columns, permethylated, and analyzed as mixtures by MALDI-TOF MS. The spectra correspond to O-glycans of MUC1F/5AC from CFT1-LC3 L28 (A) and CFT1LCFSN C13 $(B)$. The magnification is indicated above each panel. Note that magnification reductions have been used where common contaminating matrix-derived peaks occur in the low mass region of the spectrum (-). 


\begin{tabular}{|c|c|c|}
\hline $\begin{array}{l}\text { Signal } \\
(\mathbf{m} / \mathbf{z})\end{array}$ & Assignment & Predicted Structure \\
\hline 534 & $\left(\right.$ Hex $\left._{1} H_{e x N A c_{1}}\right)$-ol & \\
\hline 708 & $\left(\mathrm{Fuc}_{1} \mathrm{Hex}_{1} \mathrm{HexNAc}_{1}\right)$-ol & \\
\hline 895 & $\left(\operatorname{Neu} \mathrm{c}_{1} \mathrm{Hex}_{1} \mathrm{HexNAc}_{1}\right)$-ol & \\
\hline 983 & $\left(\mathrm{Hex}_{2} \mathrm{HexNAc}_{2}\right)-\mathrm{ol}$ & \\
\hline 1157 & $\left(\mathrm{Fuc}_{1} \mathrm{Hex}_{2} \mathrm{HexNAc}_{2}\right)$-ol & \\
\hline 1256 & $\left(\mathrm{NeuAc}_{2} \mathrm{Hex}_{1} \mathrm{HexNAc_{1 } ) - \mathrm { ol }}\right.$ & \\
\hline 1344 & $\left(\mathrm{NeuAc}_{1} \mathrm{Hex}_{2} \mathrm{HexNAc}_{2}\right.$ )-ol & \\
\hline 1432 & $\left(\mathrm{Hex}_{3} \mathrm{HexNAc}_{3}\right)_{-0 \mathrm{l}}$ & \\
\hline 1518 & $\left(\mathrm{NeuAc}_{1} \mathrm{Fuc}_{1} \mathrm{Hex}_{2} \mathrm{HexNAc}_{2}\right.$ )-ol & \\
\hline 1606 & $\left(\mathrm{Fuc}_{1} \mathrm{Hex}_{3} \mathrm{HexNAc}_{3}\right)$-ol & \\
\hline 1705 & $\left(\mathrm{NeuAc}_{2} \mathrm{Hex}_{2} \mathrm{HexNAc}_{2}\right.$ )-ol & \\
\hline 1793 & $\left(\mathrm{NeuAc}_{1} \mathrm{Hex}_{3} \mathrm{HexNAc}_{3}\right)$-ol & \\
\hline
\end{tabular}

TABLE 1. Summary of pseudomolecular ions observed in MALDI-TOF of permethylated O-glycans from the epitope-tagged MUC1F/5ACTR mucins and assignment of predicted structures. The following carbohydrate residues are represented: $\mathrm{N}$-acetylgalactosamine (filled squares); $\mathrm{N}$-acetylglucosamine (open squares); galactose (filled circles); $\mathrm{N}$-acetylneuraminic acid (open diamonds); and fucose (open triangles).

in Table 1. Further, in all cases where more than one structure could contribute to a peak, (e.g., $\mathrm{m} / \mathrm{z} 1,157, \mathrm{~m} / \mathrm{z} 1,344$, and $\mathrm{m} / \mathrm{z}$ 1,432) the components were equivalent between $\mathrm{MUC1F} /$ 5ACTR mucins made in CFT1-LC3 and CFT1-LCFSN cells (Figure 4).

\section{Evaluation of the O-Glycosylation and Sulphation of MUC1F/5ACTR by Metabolic Labeling}

The relative levels of glycosylation and sulphation of MUC1F/ 5ACTR glycoprotein purified from three CFT1-LC3 CFTRmutant cell lines (L15, L23, and L28) and three CFT1-LCFSN CFTR-corrected cell lines (C03, C13, and C16) were evaluated. The cell lines were grown to $\sim 40 \%$ confluence, washed in PBS, and labeled with ${ }^{14} \mathrm{C}$ amino acids and ${ }^{3} \mathrm{H}$ glucosamine to measure bulk O-glycosylation and with ${ }^{35} \mathrm{~S}$ sulfate and ${ }^{3} \mathrm{H}$ glucosamine to measure overall sulphation of MUC1F/5ACTR mucins. Immunoprecipitated material was separated on SDS-PAGE gels and visualized by autoradiography and the gel areas containing MUC1F/5ACTR seen in each cell line were excised. The amount of ${ }^{14} \mathrm{C}$ amino acids and ${ }^{3} \mathrm{H}$ glucosamine or ${ }^{3} \mathrm{H}$ glucosamine and ${ }^{35} \mathrm{~S}$ sulfate present on MUC1F/5ACTR was determined by scintillation counting of these excised gel slices. Ratios of ${ }^{3} \mathrm{H}$ glucosamine to ${ }^{14} \mathrm{C}$ amino acids (indicating levels of glycosylation) and of ${ }^{35} \mathrm{~S}$ sulfate to ${ }^{3} \mathrm{H}$ glucosamine (indicating levels of sulphation) were determined in a minimum of three independent labeling experiments (see Table 2).

Though the gross levels of glycosylation $\left({ }^{3} \mathrm{H} /{ }^{14} \mathrm{C}\right.$ ratio) for the MUC1F/5ACTR mucin were slightly lower in the CFT1-LC3 clones (L15, L23, and L28) (3.43-3.92) than in the wild-type CFTR corrected CFT1-LCFSN clones C03 and C16 (3.65-9.14), this difference was not statistically significant $(P=0.333, t$ test $)$. MUC1F/5ACTR mucin expressed in the $\mathrm{C} 13$ clone showed a consistently much higher level of glycosylation $\left({ }^{3} \mathrm{H} /{ }^{14} \mathrm{C}\right.$ ratio of $9.14 \pm 1.08$ ) than mucin extracted from the $\mathrm{C} 03$ and $\mathrm{C} 16$ clones; however, this is thought to reflect clonal variation.

The level of sulphation of the MUC1F/5ACTR mucin in the three CFT1-LC3 clones (L15, L23, L28) and the three CFT1LCFSN clones, C03, C13, and C16 showed no significant differences, with ${ }^{35} \mathrm{~S} /{ }^{\beta} \mathrm{H}$ ratios between $\sim 0.17$ and $0.36(P=0.827$, $t$ test). MUC1F/5ACTR mucin from individual CFTR-corrected clones showed a greater variation in sulphation levels than material derived from uncorrected clones; however, this is likely to be due to clonal variation in sulphotransferase activity.

To further evaluate the gross sulphation of the MUC1F/ 5ACTR mucin in terms of the protein backbone of the molecule, rather than per unit sugar on the glycoprotein, the ratios of ${ }^{35} \mathrm{~S}$ sulfate to ${ }^{3} \mathrm{H}$-amino acids were measured in a separate set of experiments. The levels of sulphation of MUC1F/5ACTR mucin in the three CFT1-LC3-derived clones and the three CFT1LSCFN-derived clones were similar (ratio ${ }^{35} \mathrm{~S} /{ }^{3} \mathrm{H}$-aa $0.17-0.21$, $P=0.618$ ) (Table 3).

\section{DISCUSSION}

Elucidation of the cause of the failure to clear thickened mucous secretions from the organ systems that are obstructed in $\mathrm{CF}$ could make a significant contribution to the treatment of this common genetic disease. Alterations in mucin glycosylation and sulphation in CF airway, salivary, and intestinal secretions have been reported in a number of studies using mucin purified from patients with CF $(16-18,36-38)$. However, the interpretation of these data is complicated by potential secondary modifications of the mucins that occur after secretion, for example as a result of infection and/or inflammatory responses in the epithelia. These extracellular manifestations make it difficult to differentiate the potential intracellular effects of mutant CFTR on mucin posttranslational processing. Studies of mucin processing in epithelial cell cultures derived from patients with CF should circumvent these potential secondary extracellular modifications of the mucins. Previous analyses of mucins derived from CF nasal epithelial cell cultures (19) and xenograft models (13) suggested that $\mathrm{CF}$ mucins exhibited higher levels of sulphation, and that this defect could be corrected by expression of wild-type CFTR (21); however, other data did not confirm this $(22,23)$. Several studies showed that the sulphation or glycosylation of mucins was independent of wild-type CFTR expression $(22,23)$.

The underlying cause of alterations in CF mucin glycoprotein processing has received considerable attention. One hypothesis was based on the observation that the trans-Golgi network was unusually alkaline in $\mathrm{CF}$ cells due to reduced chloride conductance $(2,11,12)$. Because glycoprotein-processing enzymes have distinct $\mathrm{pH}$ optima, this defective acidification of the Golgi would be predicted to have a significant impact on for example fucosylation, sulphation, and sialylation. However, other groups have reported that the $\mathrm{pH}$ of the trans Golgi is not influenced by expression of wild-type or mutant CFTR within cells $(14,39)$.

We investigated the processing of a single mucin type within a matched set of cell lines, which differed only with respect to CFTR expression (mutant or wild-type). Our aim was to determine whether the production of thickened mucous secretions by $\mathrm{CF}$ epithelial cells was a result of biochemical defects occurring within the cell, or arising outside the cell, following secretion into the airway/duct lumen. The latter would be consis- 
A

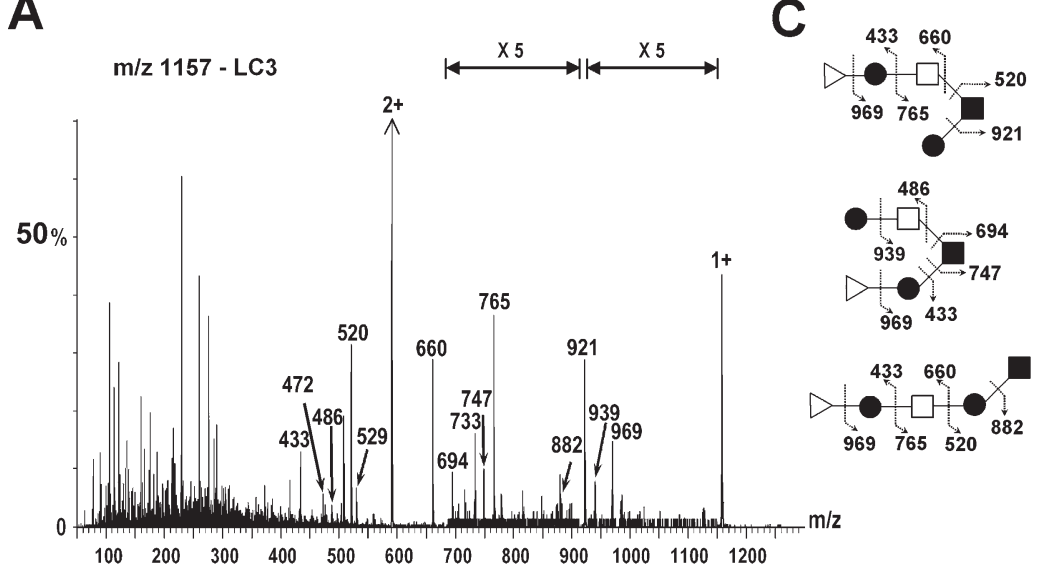

B

m/z 1157- LCFSN
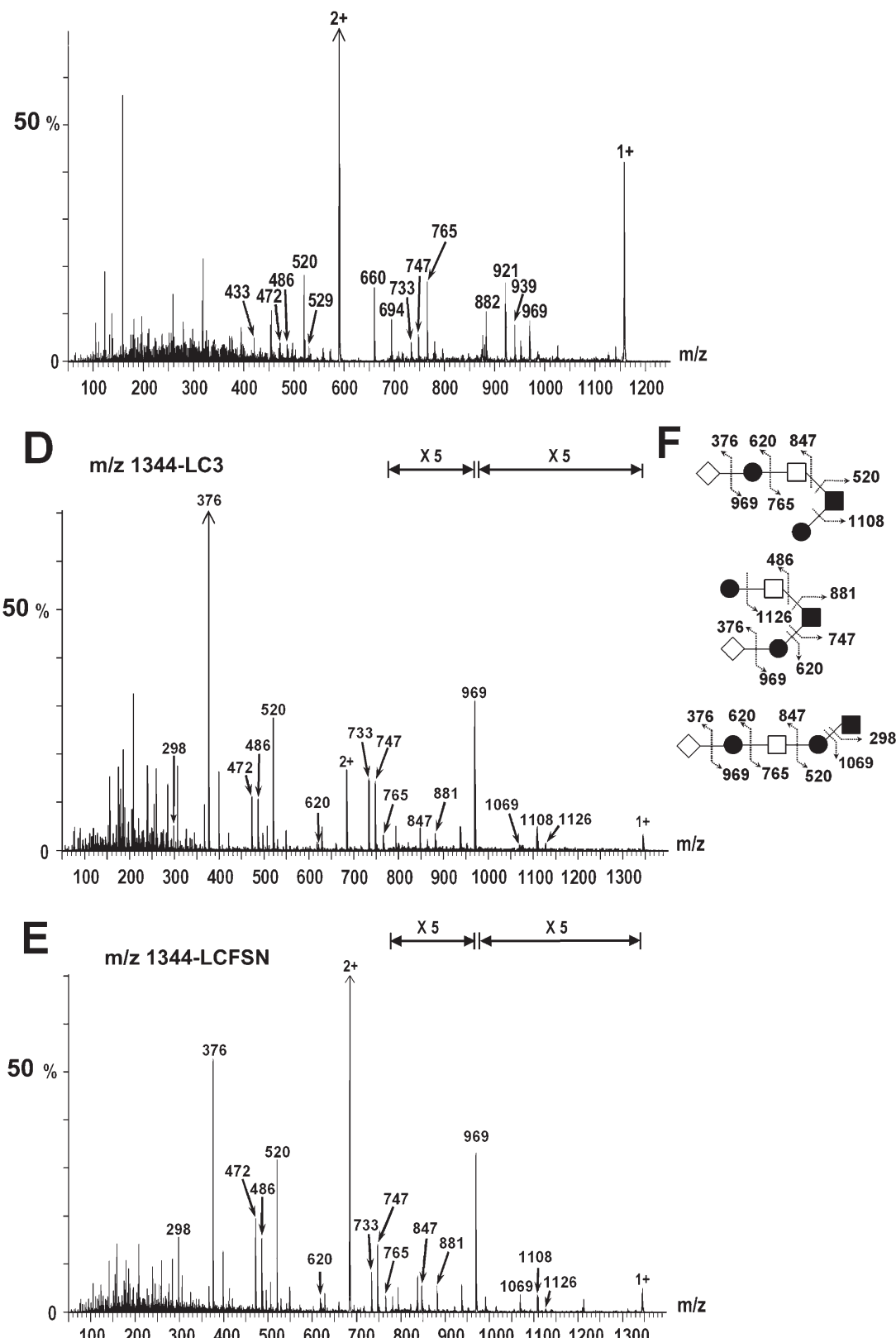

Figure 4. ES-MS/MS spectra from MUC1F/5ACTR O-glycans. Tandem electrospray mass spectrometry of permethylated O-glycans from MUC1F/5ACTR purified from CFT1-LC3 L28 and CFT1-LCFSN C13. The doublycharged ions corresponding to $\mathrm{m} / \mathrm{z} 1,157, \mathrm{~m} / \mathrm{z} 1,344$, and $\mathrm{m} / \mathrm{z} 1,432$ in Figure 3 were selected for collisional activation. CAD MS/MS spectra of $[\mathrm{M}+2 \mathrm{Na}]^{2+} \mathrm{m} / \mathrm{z} 590$, $\mathrm{m} / \mathrm{z}$ 684, and $\mathrm{m} / \mathrm{z} 728$ from CFT1-LC3 $(A, D$, and $G$, respectively) and CFT1-LCFSN ( $B, E$, and $H$, respectively) are shown. Diagnostic fragmentation ions corresponding to each type of structure are shown ( $C, F$, and $I)$. The annotated ions not assigned in the schematics at $\mathrm{m} / \mathrm{z} 472, \mathrm{~m} / \mathrm{z} 506, \mathrm{~m} / \mathrm{z} 529$, and $\mathrm{m} / \mathrm{z} 733$ correspond to double cleavages. Symbols correspond to those defined in Table 1. 

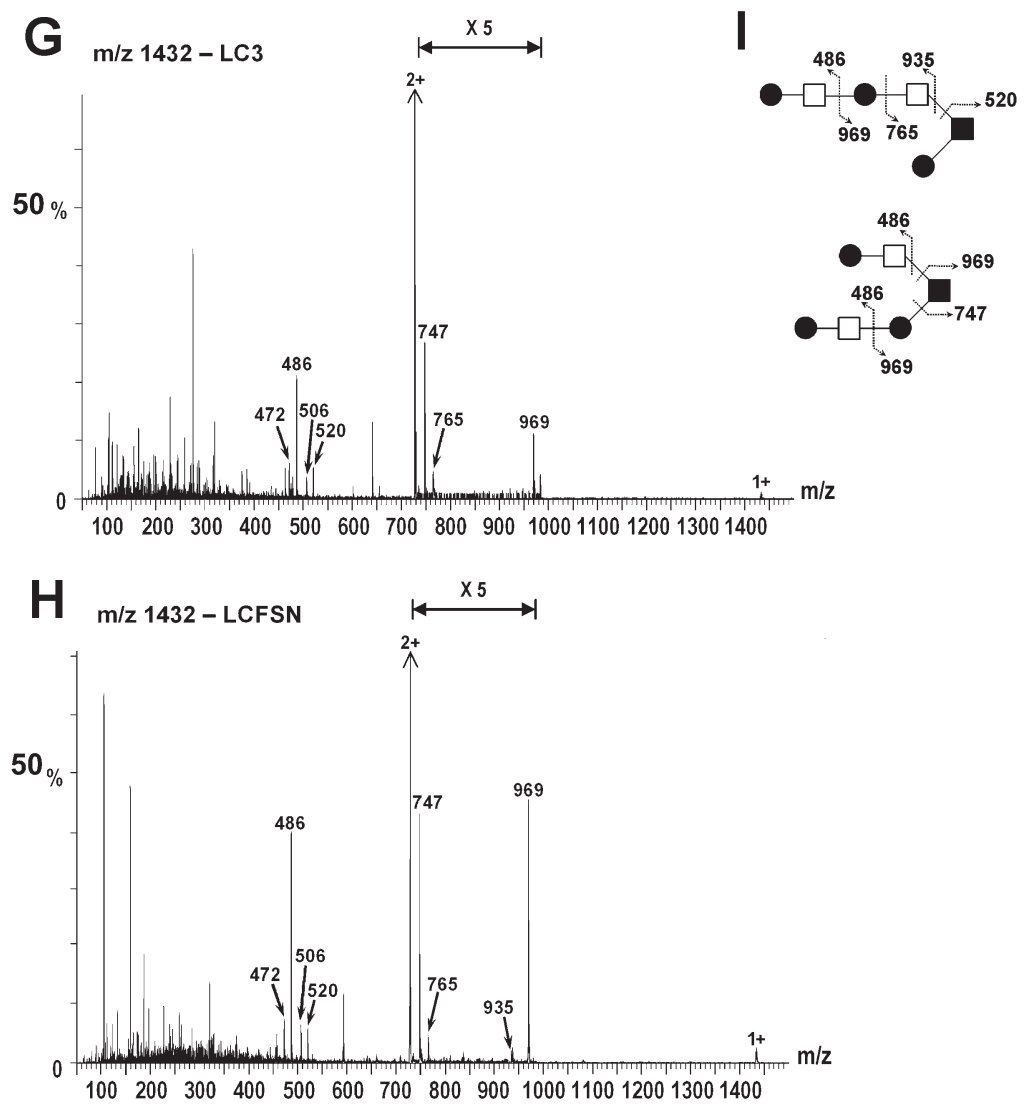

Figure 4. Continued.

tent with an altered milieu in $\mathrm{CF}$ airways causing the thickened secretions (13).

We previously showed that CFTR expression did not influence glycosylation and sulphation of MUC1 mucin in colon carcinoma cell lines (26). For the current studies we used the airway epithelial cell line CFT1-LC3 derived from a $\Delta$ F508 patient with CF and its wild-type CFTR-corrected pair CFT1-LCFSN. Before use we confirmed, using RT-PCR, that these cells lines maintained CFTR mRNA expression (Figure 2B and data not shown), in contrast to several other putative matched pairs of CFTR and CFTR + corrected airway cell lines. In addition, we used the chimeric mucin system that we have shown previously to be valid for studying the O-glycosylation of mucins $(29,34)$. We compared the O-glycosylation and sulphation of $\mathrm{MUC1F} /$ 5ACTR mucin (the TR of the major airway mucin MUC5AC carried in an epitope-tagged MUC1 mucin) stably expressed in the CFT1-LC3 and CFT1-LCSFN cells, by using a quantitative metabolic labeling assay and qualitative MS analysis. This experimental system has enabled us to ask directly, if the presence of mutant or wild-type CFTR in an airway epithelial cell directly affects the biochemical properties of a single mucin glycoprotein.

\section{CFTR Expression Causes No Qualitative Difference in the O-glycans of MUC1F/5ACTR}

Preliminary data from Western blot evaluation of the MUC1F/ 5ACTR mucins expressed in the CFT1-LC3 and CFT1-LCFSN lines suggested that there were no gross differences in their sialylation or sulphation because all glycoforms showed similar migration irrespective of their CFTR status. Sialylation and sulphation are known to affect the mobility of molecules in SDSPAGE (40).

We previously used antibodies directed against carbohydrate

TABLE 2. GLYCOSYLATION OF AMINO ACIDS AND SULPHATION OF GLYCANS ON MUC1F/5ACTR IN CFTR MUTANT AND CFTR-CORRECTED CELL LINES

\begin{tabular}{|c|c|c|c|c|}
\hline Clones & MUC1F/5ACTR Expression & CFTR Expression & ${ }^{3} \mathrm{H} /{ }^{14} \mathrm{C}$ & ${ }^{35} \mathrm{~S} /{ }^{3} \mathrm{H}$ \\
\hline $\mathrm{C} 03$ & Low & WT corrected & $3.78 \pm 0.61$ & $0.36 \pm 0.11$ \\
\hline $\mathrm{C} 13$ & High & WT corrected & $9.14 \pm 1.08$ & $0.17 \pm 0.05$ \\
\hline C16 & High & WT corrected & $3.65 \pm 0.25$ & $0.22 \pm 0.00$ \\
\hline L15 & Low & $\Delta \mathrm{F} 508$ mutant & $3.43 \pm 0.60$ & $0.27 \pm 0.11$ \\
\hline L23 & High & $\Delta \mathrm{F} 508$ mutant & $3.92 \pm 0.46$ & $0.27 \pm 0.02$ \\
\hline L28 & High & $\Delta \mathrm{F} 508$ mutant & $3.78 \pm 0.61$ & $0.25 \pm 0.11$ \\
\hline
\end{tabular}

Definition of abbreviations: CFTR, cystic fibrosis transmembrane conductance regulator; WT, wild-type.

Results are shown as ratios of $\mathrm{d}-\left[6-{ }^{3} \mathrm{H}\right]$ glucosamine hydrochloride (glucosamine) to $\left[\mathrm{U}-{ }^{14} \mathrm{C}\right]$ protein hydrolysate (amino acids) and ${ }^{35} \mathrm{~S}$-sodium sulphate to $\mathrm{d}-\left[6-{ }^{3} \mathrm{H}\right]$ glucosamine $\left({ }^{35} \mathrm{~S} /{ }^{3} \mathrm{H}\right.$, sulphation) and $\pm \mathrm{SEM}$. $P$ value between WT corrected clones and $\Delta \mathrm{F} 508$ mutant clones, $t$ test: ${ }^{3} \mathrm{H} /{ }^{14} \mathrm{C}, P=0.333 ;{ }^{35} \mathrm{~S} /{ }^{3} \mathrm{H}, P=0.827$. Data are derived from three separate experiments with triplicate cultures of each clone. 
TABLE 3. TOTAL MUC1F/5ACTR SULPHATION IN CFTR MUTANT AND CFTR-CORRECTED CELL LINES

\begin{tabular}{llll}
\hline Clones & MUC1F/5ACTR Expression & CFTR Expression & ${ }^{35} \mathrm{~S} /{ }^{3} \mathrm{H}$-aa \\
\hline C03 & Low & WT corrected & $0.20 \pm 0.04$ \\
C13 & High & WT corrected & $0.18 \pm 0.03$ \\
C16 & High & WT corrected & $0.17 \pm 0.05$ \\
L15 & Low & $\Delta$ F508 mutant & $0.18 \pm 0.08$ \\
L23 & High & $\Delta$ F508 mutant & $0.21 \pm 0.11$ \\
L28 & High & $\Delta$ F508 mutant & $0.18 \pm 0.06$
\end{tabular}

For definition of abbreviations see Table 2 .

Results are shown as ratios of ${ }^{35} \mathrm{~S}$-sodium sulphate to $\left[{ }^{3} \mathrm{H}\right]$ amino acids $\pm \mathrm{SEM}$. $P$ value between WT corrected clones and $\Delta$ F508 mutant clones, $t$ test: $P=0.618$. Data were collected from two separate experiments with triplicates of each clone.

structures to show that CFTR expression does not influence $\mathrm{O}$-glycosylation of the epitope-tagged MUC1F in colon carcinoma cells (26). The current data confirm this and extend the studies by using MALDI-TOF and ES mass spectrometry to examine the carbohydrate structures in detail. Evaluation of the MUC1F/ 5ACTR chimeric mucin by MALDI-TOF mass spectrometry to determine the O-glycan compositions carried by this molecule indicated that no novel O-glycan structures were present in either the CFT1-LC3 or CFT1-LCFSN-derived cell lines. All 12 O-glycans detected in CFTR mutant cells were also seen in cells that expressed wild-type CFTR. Though some minor differences were seen in the abundance of a few of the peaks, these are likely to reflect individual clonal variation or sample abundance differences rather than a consistent difference between the CFTR+ and CFTR - lines. If there was a relative increase in mucin fucosylation associated with $\mathrm{CF}$, then either additional fucosylated derivates would be observed in the CFT1-LC3 clones, and/ or the relative abundance (in comparison to similar $\mathrm{m} / \mathrm{z}$ peaks that are not fucosylated) of the $\mathrm{m} / \mathrm{z} 708, \mathrm{~m} / \mathrm{z} 1,157$, and $\mathrm{m} / \mathrm{z}$ 1,606 would be increased. This does not appear to be the case. Similarly, the decrease in sialylation that has been reported for mucins synthesized in CF cells would predict a relative decrease in the abundance (in comparison to similar $\mathrm{m} / \mathrm{z}$ peaks that are nonsialylated) of peaks at m/z 895, m/z 1,256, m/z 1,344, m/z $1,518, \mathrm{~m} / \mathrm{z} 1,705$, and $\mathrm{m} / \mathrm{z} 1,793$. Again, this is not observed and variations in abundance are seen in core 1 and sialylated or fucosylated core 2 structures rather than the variable peaks all carrying same modification. Additional structural information was obtained by CAD ES tandem mass spectrometry of selected pseudomolecular ions. In each case where peaks could contain a mixture of glycans, these were of similar abundance in the CFT1-LC3 and CFT1-LCFSN clones. It is of interest that the glycans seen on the MUC1F-derived mucins in the 16HBE140cell line, an SV40-transformed airway cell line, show significant differences from those detected here in the CFT1-LC3 and CFT1-LCSFN airway lines $(41,42)$. This further illustrates the importance of carrying out this type of study in appropriately matched cell strains. The failure to detect consistent differences in the glycosylation, including the fucosylation and sialylation of MUC1F/5ACTR expressed in CFTR mutant and wild-type corrected airway epithelial cells, suggests that mucin abnormalities observed in CF secretions are not caused by intracellular events that alter the glycoprotein processing machinery.

\section{CFTR Expression Causes No Quantitative Differences in the O-Glycosylation or Sulphation of MUC1F/5ACTR}

Because MALDI mass spectroscopy is not a definitively quantitative technique, we next examined gross glycosylation and sulphation of MUC1F/5ACTR in $\triangle$ F508 CFTR (CFT1-LC3) and WT CFTR CFT1-LCFSN cells by metabolic labeling. Individual clones derived from the same parental cell line may express different phenotypic characteristics in culture. Further, the clonal variation in glycoprotein processing enzymes has been illustrated previously (23); hence, we performed metabolic labeling experiments in three clones each of CFT1-LC3 and CFT1-LCFSN expressing MUC1F/5ACTR. First, ratios of $\left[{ }^{3} \mathrm{H}\right]$-glucosamine to $\left[{ }^{14} \mathrm{C}\right]$-amino acids $\left({ }^{3} \mathrm{H} /{ }^{14} \mathrm{C}\right)$ were measured to quantify the overall $\mathrm{O}$-glycosylation. The gross levels of O-glycosylation of $\mathrm{MUC1F} /$ 5ACTR chimeric mucin did not differ significantly in the CFT1LC3 and CFT1-LCFSN cell lines, except that a 2-fold increase in the ${ }^{3} \mathrm{H} /{ }^{14} \mathrm{C}$ ratio was consistently observed in the CFT1-LCFSN clone $\mathrm{C} 13$. This indicates a high level of glycosylation that is likely to be an example of clonal variation in the glycosylation machinery, as it was not observed in the $\mathrm{C} 03$ or $\mathrm{C} 16$ clones. Next, we compared the ratios of $\left[{ }^{35} \mathrm{~S}\right]-\mathrm{Na}_{2} \mathrm{SO}_{4}$ to $\left[{ }^{3} \mathrm{H}\right]$-glucosamine $\left({ }^{35} \mathrm{~S} /{ }^{3} \mathrm{H}\right)$ as a measure of overall sulphation of glycans. Finally, the overall sulphation of the MUC1F/5ACTR glycoprotein was evaluated by comparing the ratios of $\left[{ }^{35} \mathrm{~S}\right]-\mathrm{Na}_{2} \mathrm{SO}_{4}$ to $\left[{ }^{3} \mathrm{H}\right]$-amino acids $\left({ }^{35} \mathrm{~S} /{ }^{3} \mathrm{H}\right.$-aa) in the same culture. Neither method revealed a significant difference in the gross levels of sulphation of the MUC1F/5ACTR mucin expressed in mutant or wild-type CFTR airway cells.

In conclusion, using an airway cell culture system, with two cell lines that differ only with respect to mutant or wild-type CFTR expression, we found no qualitative (by mass spectrometry) or quantitative (by metabolic labeling) evidence for a direct link between O-glycosylation (including sialylation and fucosylation) or sulphation of a single mucin type and normal CFTR expression. Thus, our data, which are in agreement with another recent study (43), fail to support the hypothesis that the thickened mucous secretions characteristic of the CF respiratory system arise due to primary defects in mucin biochemistry that result from the absence of wild-type CFTR in the cell. Rather, these data are consistent with the mucin abnormalities arising outside the airway epithelial cell, most probably as a secondary effect of the altered airway surface liquid in CF.

Conflict of Interest Statement: S.-H.L. has no declared conflicts of interest; S.P. has no declared conflicts of interest; T.P.-P. has no declared conflicts of interest; J.E. has no declared conflicts of interest; H.R.M. has no declared conflicts of interest; A.D. has no declared conflicts of interest; and A.H. has no declared conflicts of interest;

Acknowledgments: The authors thank Dr. J. Yankaskas for the CFT1-LC3 and CFT1-LCFSN cell lines and Dr. M. A. Hollingsworth for helpful discussions.

\section{References}

1. Hollingsworth MA, Swanson BJ. Mucins in cancer: protection and control of the cell surface. Nat Rev Cancer 2004;4:45-60.

2. Barasch J, al Awqati Q. Defective acidification of the biosynthetic pathway in cystic fibrosis. J Cell Sci Suppl 1993;17:229-233.

3. Parmley RR, Gendler SJ. Cystic fibrosis mice lacking Muc1 have reduced amounts of intestinal mucus. J Clin Invest 1998;102:1798-1806.

4. Picot R, Das I, Reid L. Pus, deoxyribonucleic acid, and sputum viscosity. Thorax 1978;33:235-242.

5. Reid L. Sputum viscosity in cystic fibrosis. Lancet 1970;2:423-424.

6. Charman J, Reid L. Sputum viscosity in chronic bronchitis, bronchiectasis, asthma and cystic fibrosis. Biorheology 1972;9:185-199.

7. Jayaraman S, Joo NS, Reitz B, Wine JJ, Verkman AS. Submucosal gland secretions in airways from cystic fibrosis patients have normal $[\mathrm{Na}(+)]$ and pH but elevated viscosity. Proc Natl Acad Sci USA 2001;98:81198123.

8. Puchelle E, Jacquot J, Beck G, Zahm JM, Galabert C. Rheological and transport properties of airway secretions in cystic fibrosis-relationships with the degree of infection and severity of the disease. Eur J Clin Invest 1985:15:389-394.

9. Lethem MI, James SL, Marriott C. The role of mucous glycoproteins in the rheologic properties of cystic fibrosis sputum. Am Rev Respir Dis 1990;142:1053-1058. 
10. Chace KV, Naziruddin B, Desai VC, Flux M, Sachdev GP. Physical properties of purified human respiratory mucus glycoproteins: effects of sodium chloride concentration on the aggregation properties and shape. Exp Lung Res 1989;15:721-737.

11. Barasch J, Kiss B, Prince A, Saiman L, Gruenert D, al Awqati Q. Defective acidification of intracellular organelles in cystic fibrosis. Nature 1991;352:70-73

12. al Awqati Q, Barasch J, Landry D. Chloride channels of intracellular organelles and their potential role in cystic fibrosis. J Exp Biol 1992; 172:245-266.

13. Tarran R, Grubb BR, Parsons D, Picher M, Hirsh AJ, Davis CW, Boucher RC. The CF salt controversy: in vivo observations and therapeutic approaches. Mol Cell 2001;8:149-158.

14. Seksek O, Biwersi J, Verkman AS. Evidence against defective transGolgi acidification in cystic fibrosis. J Biol Chem 1996;271:1554215548 .

15. Smith JJ, Travis SM, Greenberg EP, Welsh MJ. Cystic fibrosis airway epithelia fail to kill bacteria because of abnormal airway surface fluid. Cell 1996;85:229-236.

16. Wesley A, Forstner J, Qureshi R, Mantle M, Forstner G. Human intestinal mucin in cystic fibrosis. Pediatr Res 1983;17:65-69.

17. Frates RC Jr, Kaizu TT, Last JA. Mucus glycoproteins secreted by respiratory epithelial tissue from cystic fibrosis patients. Pediatr Res 1983; 17:30-34.

18. Carnoy C, Ramphal R, Scharfman A, Lo-Guidice JM, Houdret N, Klein A, Galabert C, Lamblin G, Roussel P. Altered carbohydrate composition of salivary mucins from patients with cystic fibrosis and the adhesion of Pseudomonas aeruginosa. Am J Respir Cell Mol Biol 1993;9: 323-334.

19. Cheng PW, Boat TF, Cranfill K, Yankaskas JR, Boucher RC. Increased sulfation of glycoconjugates by cultured nasal epithelial cells from patients with cystic fibrosis. J Clin Invest 1989;84:68-72.

20. Zhang Y, Doranz B, Yankaskas JR, Engelhardt JF. Genotypic analysis of respiratory mucous sulfation defects in cystic fibrosis. J Clin Invest 1995;96:2997-3004.

21. Zhang Y, Jiang Q, Dudus L, Yankaskas JR, Engelhardt JF. Vectorspecific complementation profiles of two independent primary defects in cystic fibrosis airways. Hum Gene Ther 1998;9:635-648.

22. Hill WG, Harper GS, Rozaklis T, Hopwood JJ. Sulfation of chondroitin/ dermatan sulfate by cystic fibrosis pancreatic duct cells is not different from control cells. Biochem Mol Med 1997;62:85-94.

23. Jiang X, Hill WG, Pilewski JM, Weisz OA. Glycosylation differences between a cystic fibrosis and rescued airway cell line are not CFTR dependent. Am J Physiol 1997;273:L913-L920.

24. Emery N, Lo-Guidice JM, Lafitte JJ, Lhermitte M, Roussel P. The fucosylation and secretion of mucins synthesized in human bronchial cells vary according to growth conditions. Glycobiology 1997;7:95-101.

25. Brockhausen I, Vavasseur F, Yang X. Biosynthesis of mucin type O-glycans: lack of correlation between glycosyltransferase and sulfotransferase activities and CFTR expression. Glycoconj J 2001;18: 685-697.

26. Reid CJ, Burdick MD, Hollingsworth MA, Harris A. CFTR expression does not influence glycosylation of an epitope-tagged MUC1 mucin in colon carcinoma cell lines. Glycobiology 1999;9:389-398.

27. Thornton DJ, Carlstedt I, Howard M, Devine PL, Price MR, Sheehan
JK. Respiratory mucins: identification of core proteins and glycoforms. Biochem J 1996;316:967-975.

28. Asker N, Axelsson MA, Olofsson SO, Hansson GC. Human MUC5AC mucin dimerizes in the rough endoplasmic reticulum, similarly to the MUC2 mucin. Biochem J 1998;335:381-387.

29. Silverman HS, Parry S, Sutton-Smith M, Burdick MD, McDermott K, Reid CJ, Batra SK, Morris HR, Hollingsworth MA, Dell A, et al. In vivo glycosylation of mucin tandem repeats. Glycobiology 2001; 11:459-471.

30. Olsen JC, Johnson LG, Stutts MJ, Sarkadi B, Yankaskas JR, Swanstrom $\mathrm{R}$, Boucher RC. Correction of the apical membrane chloride permeability defect in polarized cystic fibrosis airway epithelia following retroviral-mediated gene transfer. Hum Gene Ther 1992;3:253-266.

31. Yankaskas JR, Haizlip JE, Conrad M, Koval D, Lazarowski E, Paradiso AM, Rinehart CA Jr, Sarkadi B, Schlegel R, Boucher RC. Papilloma virus immortalized tracheal epithelial cells retain a well-differentiated phenotype. Am J Physiol 1993;264:C1219-C1230.

32. Chambers JA, Harris A. Expression of the cystic fibrosis gene and the major pancreatic mucin gene, MUC1, in human ductal epithelial cells. J Cell Sci 1993;105:417-422.

33. Mouchel N, Henstra SA, McCarthy VA, Williams SH, Phylactides M, Harris A. HNF1alpha is involved in tissue-specific regulation of CFTR gene expression. Biochem J 2004;378:909-918.

34. Silverman HS, Sutton-Smith M, McDermott K, Heal P, Leir SH, Morris HR, Hollingsworth MA, Dell A, Harris A. The contribution of tandem repeat number to the O-glycosylation of mucins. Glycobiology 2003; 13:265-277.

35. Dell A, Morris HR. Glycoprotein structure determination by mass spectrometry. Science 2001;291:2351-2356.

36. Roussel P, Lamblin G, Degand P. Heterogeneity of the carbohydrate chains of sulfated bronchial glycoproteins isolated from a patient suffering from cystic fibrosis. J Biol Chem 1975;250:2114-2122.

37. Mergey M, Lemnaouar M, Veissiere D, Perricaudet M, Gruenert DC, Picard J, Capeau J, Brahimi-Horn MC, Paul A. CFTR gene transfer corrects defective glycoconjugate secretion in human $\mathrm{CF}$ epithelial tracheal cells. Am J Physiol 1995;269:L855-L864.

38. Chace KV, Flux M, Sachdev GP. Comparison of physicochemical properties of purified mucus glycoproteins isolated from respiratory secretions of cystic fibrosis and asthmatic patients. Biochemistry 1985;24: 7334-7341.

39. Gibson GA, Hill WG, Weisz OA. Evidence against the acidification hypothesis in cystic fibrosis. Am J Physiol Cell Physiol 2000;279: C1088-C1099.

40. Litvinov SV, Hilkens J. The epithelial sialomucin, episialin, is sialylated during recycling. J Biol Chem 1993;268:21364-21371.

41. Cozens AL, Yezzi MJ, Kunzelmann K, Ohrui T, Chin L, Eng K, Finkbeiner WE, Widdicombe JH, Gruenert DC. CFTR expression and chloride secretion in polarized immortal human bronchial epithelial cells. Am J Respir Cell Mol Biol 1994;10:38-47.

42. Silverman HS, Sutton-Smith M, Heal P, Parry S, Palmai-Pallag T, Leir $\mathrm{SH}$, Morris HR, Dell A, Harris A. In vivo glycosylation of MUC1 in airway epithelial cells. Glycoconj J 2002;19:379-384.

43. Holmen JM, Karlsson NG, Abdullah LH, Randell SH, Sheehan JK, Hansson GC, Davis CW. Mucins and their O-Glycans from human bronchial epithelial cell cultures. Am J Physiol Lung Cell Mol Physiol 2004;287:L824-L834. 